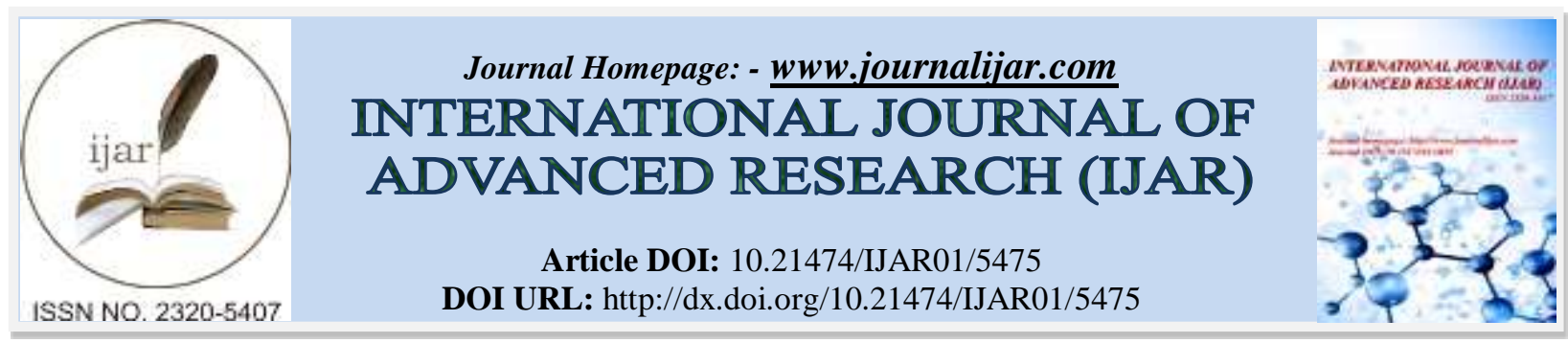

RESEARCH ARTICLE

\title{
A STUDY ABOUT LOSS OF COSTS OF MAINTENANCE FOR EQUIPMENT BY USING TAGUCHI METHOD OF QUALITY CONTROL.
}

\author{
Abdulkhalek M. Kadir. \\ Erbil Technical Engineering College, Erbil Polytechnic University-Iraq.
}

\section{Manuscript Info}

Manuscript History

Received: 19 July 2017

Final Accepted: 21 August 2017

Published: September 2017

Key words:-

Maintenance, $X$-Bar Control Chart, Loss Of Costs, Quality Level, Taguchi Method Of Quality Control.

\begin{abstract}
Control chart is a main tool in statistical process control, it is used to promote quality level of maintenance of equipment in the firms, and it can assure loss of costs to be as lower average cost of maintenance when Taguchi method of quality control is used and by several mathematical equations in the process. As a result of huge development of equipment, the production shifted from workers to machines, then the role of maintenance much increased, and failure rates and defects amount become proportional to higher quality level of applied maintenance. As a new subject, the research tries to combine four factors of maintenance, loss of costs, x-bar control chart, and quality level, then to present equations or formulas of four types of loss of costs in order to find their values. As a new methodology, the research will aim at minimizing loss of costs, achieving small average cost of maintenance procedure in the firms, and sorting them by using Taguchi method of quality control with six of related equations.
\end{abstract}

Copy Right, IJAR, 2017,. All rights reserved.

\section{Nomenclature:-}

The following abbreviations are the Nomenclature and their explanations which are used in the research:

s: sample size.

$h$ : interval between successive subgroups.

$k$ : control limit coefficient of control chart or control width.

$\mu$ : process mean.

u: a production quantity per unit time.

w: warning coefficient.

Explanation: it is the warning coefficient, or maintenance threshold, it is warning width, and in this research, we assign $w$ as two third of the magnitude of control width $k$.

$\beta$ : the standard deviation of the process in-control state.

$C_{p o} / \Delta^{2}:$ the coefficient of loss function.

$\mu 0$ : in-control process means.

11: out-of-control condition.

$\delta$ : value for the shift.

$d v$ : the difference between the average and target in-control state.

$P_{w}$ : the probability when the process is under control state and there is no any extra action required.

$P_{r}$ : the probability when the process is under control state but the process mean falls in the warning zone.

$\Omega(\cdot)$ : a cumulative density function of normal distribution. 
h: sampling interval.

$T_{c m}$ : average maintenance time.

Explanation: it is the average maintenance time, or it is required elapsed time for each maintenance action.

$h_{0}:$ the expected sampling interval.

$\psi:$ the average time of occurrence of the assignable cause within an interval.

$T_{0}$ : the mean time during which the process is in the beginning to the first sampling after the process shifts.

$M_{P}$ : magnitude of process mean shift if an assignable cause occurs.

$\overline{P_{w}}:$ the probability that the mean falls inside warning control limit.

$\overline{P_{r}}:$ the probability that the mean falls between the warning and control limit.

$h_{1}$ : the expected sampling interval when the process is out-of-control state.

$A R L_{1}$ : the average-run length when the process shifts to the out of control state.

$T_{1}$ : the expected time interval within the faulty process.

$T_{\text {tap: }}$ it is a constant average time to testing the sample, analyzing the results, and plotting.

Explanation: it is another time for testing the sample, analyzing the results and plotting is considered as a constant time (denoted as e).

Tr: it is the constant average time for repairing but after the assignable cause has been identified.

Explanation: it is the average time to bring a process back to an in-control state after assignable cause has been identified.

$\rho$ : the type 1 error probability.

$C_{p i}$ : average cost perfalse alarm when process is in-control, or it is the average cost per false alarm.

$C_{f u}$ : fixed sampling cost per unit or it is the cost of taking a sample that is independent of the sample size.

$C_{v u}$ : variable sampling cost per unit or it is the variable cost per item for sampling, testing and plotting.

Cr: cost to locate and repair an assignable cause, or it is the cost of finding and repairing the assignable cause each time.

$C_{a c m}:$ the average cost per corrective maintenance action.

$\Delta \pm m:$ the specification limit of quality characteristic.

$\Delta$ : the width of specification limit of quality characteristic.

$m$ : the target value.

$\Delta / m$ : Then we can obtain the value of $(\Delta / m)$ for the coefficient of loss function.

$C_{p o}$ : average increasing cost when process is out-of-control, or it is a penalty loss cost due to a greater percentage for repairing equipment being outside the control limits.

$Q:$ the loss per item (equipment) in an average cycle procedure.

Q1: the loss cost of a false signal detection, sampling, inspecting, evaluating, plotting and actually finding, and repairing the assignable cause.

Q2: the cost of corrective maintenance.

Q3: the in-control average social loss.

Q4: the expected social loss due to poor quality.

\section{Introduction and literature review:-}

The control chart is an important tool of statistical process control SPC, it can be used to detect process shifts in both line of mean and variance [1], this tool can monitor and indicate the loss of costs and it can show if the maintenance procedure is not under the statistical control, when the maintenance is not under the statistical control, the corrective action will be done in order to prevent further happening of nonconforming maintenance of equipment in the firm. The maintenance under statistical control is used to achieve maintenance with higher quality level; hence, the $\mathrm{x}$ control chart is used as a main tool for the purpose related to maintenance of equipment. Also, the control chart will give greater chance to designate a model for economic design to evaluate statistical criteria in the maintenance procedure, and the first model of economic design of $\mathrm{x}$ control charts is applied by the researcher, later he extends his research from single to multiple assignable causes in which the failure mechanism is assumed to be an exponential distribution [2], in addition, it can really give lower time and lower cost when compared with Shewhart's model, and an optimum methodology to get three economic design parameters of sample size $(s)$, sampling interval $(h)$ and control-limit width $(+\&-\mathrm{k}$ standard deviation), this initial model is made for minimizing loss cost, sampling cost, testing cost, repairing cost, false alarm cost, searching cost, and an increasing cost from out-of-control process [3, 4]. 


\section{Review of previous studies:-}

Several previous studies have achieved to improve control chart application, and so as to find loss of costs, after Duncan's initial study, there were many studies prepared by researchers about economic design of control charts, then an optimization procedure was developed for determining loss of costs parameters for the x-bar control chart [5], in more details, other studies presented to find economic design of an $\mathrm{x}$ - control chart, but a periodic inspection was added to possible employing a regular $x$-chart for different situations [6], but with connection with repairing, another study tried to connect repair of equipment with loss of costs, and the results showed a model to apply in the maintenance during repair for assignable cause loss of costs [7]. In a review of literatures made by several studies on loss of costs of maintenance between years 1981-1991, they used economic design of control charts, and they observed lack of confidence in precision of the input parameters, they proposed for a theoretical development in the area of loss of costs [8], for more improved function, researches used Taguchi method to find target of loss of costs $[9,10]$.

\section{Review of recent studies:-}

Several recent studies have achieved to improve or complete results of previous studies, and in order to show that there are developments about this topic to achieve more theoretical area of loss of costs, with considering Duncan's cost model, a study "made by Engin- 2004" was developed in an application of economic statistical x-control chart in the textile yarn industry, and for optimum $\mathrm{n}, \mathrm{h}$, and $\mathrm{k}$ the researcher considered the power of control chart to be at least 0.95 , and the penalty-cost will be minimal as possible [11]. Other studies developed a model of "LorenzenVance cost model" to determine economic utility, an average quality cost was analyzed and the model was generalized and Duncan's model issued in 1956, so it was directly applicable to most types of control charts, and the "Lorenzen - Vance cost model" with higher quality was adopted [12]. Then, a study developed a software package in $\mathrm{R}$ chart with a new name for economic design of control chart in 2013, and then a tablet production process was analyzed for economic design of control charts in industrial application [13].

\section{Taguchi method of quality control:-}

The Japanese engineer-statistician, Dr. Genichi Taguchi developed Taguchi method, the method is defined as a quality control methodology, it combines control chart, process control and process design with maintenance procedure in order to achieve a robust total design, the method can assist to obtain high quality level of maintenance procedures as an experimental study determined and developed a statistical method [14], at later time, the method has been improved and used for many fields of engineering, it involved control factors to obtain optimum results of manufacturing process [15]. Taguchi method can recognize role of the research and development in reducing the occurrence of defects, failures, and loss of costs which have fest relation with maintenance of equipment in the firms, because the main contribution of Taguchi method lies in several quality improvement techniques and mathematical formulas which will be not affected by outside conditions and daily variations of equipment, and to improve quality level. Taguchi method emphasis on minimizing variations [16]. As practical side, the method has a graphical representation of non-perfect parts which can lead to an overall loss of costs of maintenance in the firm, and to give results approach to reduce or eliminate waste, losses in production, and rework, but there is an interrelation among Taguchi method, quality control, and quality [17]. Taguchi method can overcome bad design of maintenance of equipment, because it assists to increase inspection and uses statistical procedures during manufacturing phases [18], it takes four procedures such as: (1) definition of all relevant factors specific for the optimization problem and their values, (2) selection of suitable fields for control factors, among standard factors or their modifications, (3) conducting experiments and analysis of results, (4) conducting of the verifiable experiments, which should confirm improvement that occurs by optimum combination of factors [19].

\section{Options of new developments:-}

After great development of production machines, technology of equipment, using of automated machines and robots in the firms, the process of manufacturing was shifted from workers to equipment, therefore the role of maintenance of equipment increased and turn out to be more important than before to give continual production and to reduce stoppage of equipment during operations, this was lead to control main options of quantity, quality, time, and cost of manufacturing equipment in the firms, and nowadays most academicians and technicians recognize that there is strong relationship between product quality and maintenance of equipment [20]. The new developments came also by interrelation between control chart and maintenance, it was maximized, and many studies affirmed that the actual integration between control chart and maintenance become more beneficial to firms, they determined jointly optimal design parameters on $\mathrm{x}$-bar control chart and the loss of costs of maintenance procedures [21]. Further developments were made by studies, they prepared economic design of control chart to be essential basic to maintenance of 
equipment in the firms, then so as to reduce loss of costs, and they developed an integrated model of control chart and maintenance management [22].

\section{Parameters and variables:-}

In relation with the topic loss of costs, there are 37 parameters and variables which can inserted into the economic design of control chart to find loss of costs in the maintenance of equipment in the firm, they are expressed as symbols (as mentioned in Nomenclature), in addition, there are some decision variables and other parameters which are noted in other references [3]. But as a rule, there are three variables, they should be selected and assist to monitor and calculate loss of costs of maintenance after designing $\mathrm{x}$-control chart, they are subgroup size $(s)$, interval between successive subgroups $(h)$, control limits $(k)$, and warning coefficient or corrective threshold $(w)$ and most studies assumed them as decision variables in any economic design models [23, 24].

\section{Aims of the research:-}

The research tries to:

- Indicate review of previous and recent studies on the topic of loss of costs

- Show the loss of costs of maintenance of equipment in the firm, to find values of four loss of costs of maintenance, to achieve the goals of the research which are the same as control chart, and to show how minimum loss of costs to be?

- Indicate the sorts of costs of maintenance which are many losses occurred by using Taguchi method of quality control, and to show mathematical equations of costs, this can be loss in maintenance process, and how the process shifts from the original state.

\section{Methodology of the research:-}

To get the aims, the research presents a methodology which consists of several steps such as:

- Collecting sorts of loss of costs named by previous and recent studies.

- Finding level values of loss of costs of maintenance procedure.

- Using Taguchi method of quality control to indicate the shifts during maintenance procedure.

- Presenting options of new developments, 3 decision variables, and 25 parameters to assist determining loss of costs in equipment maintenance.

- Indicating related mathematical equations of 6 formulas to show how to find values of a four-loss of costs, and how to be measured?

\section{Loss of costs:-}

When designing a control chart dimensions, the loss of costs will take important role, and the value should be determined and computed to assist the maintenance system in the firm, this will be done in order to achieve oncontrol state with high quality characteristics of the operating equipment, both operation of equipment and their inspection are performed in which having influence on maintenance procedures. In the designated control chart, the aim is to fix a value for the shift $\delta$ of in-control process means $\mu 0$ to out-of-control condition $\mu 1$, and the selecting correct value for shift size can be assumed as a difficult decision tackled by the quality practitioner, due to the lack of former process knowledge [24], therefore, there is a condition that any further maintenance procedure is not required if the overall process is under control state and the quality characteristic is located between zones of $(\mu \pm w$ $\beta / \sqrt{s}$ ), and the assign $w$ is two third of the magnitude of control width $k$. Figure 1 shows the cost with Taguchi method and traditional cost function. 


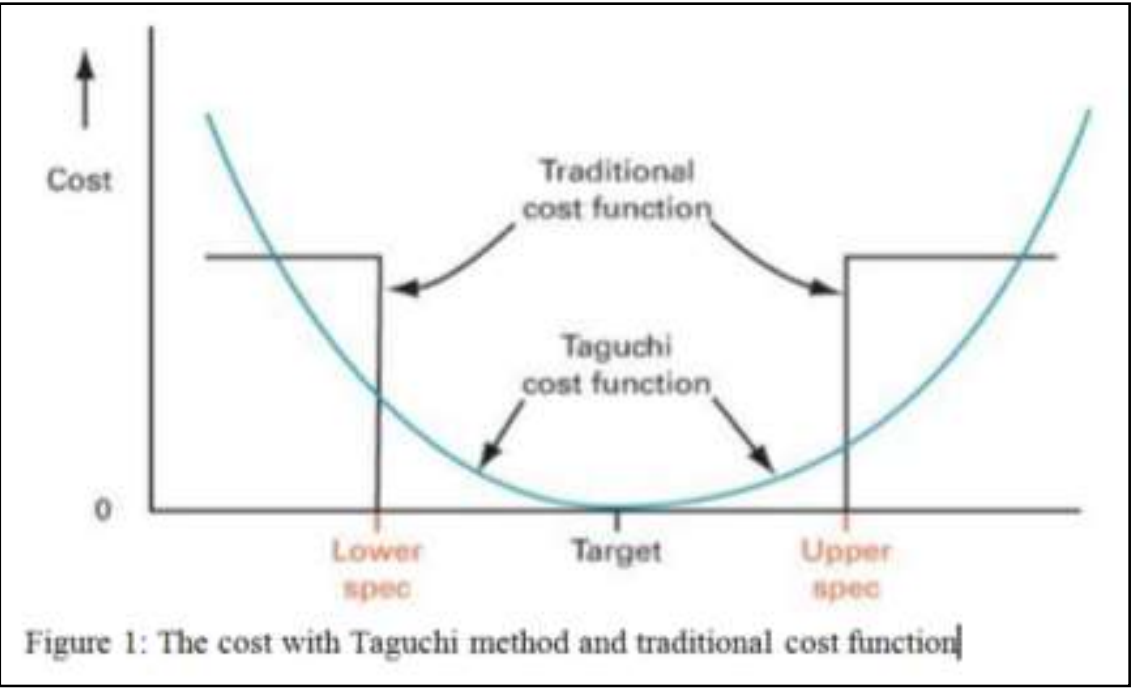

In all cases, obtaining minimum costs of maintenance procedure will remain as a main goal of economic design of control charts; this will satisfy firm's management about efficient operated equipment. Within maintenance procedure, there are several related costs, and there will be an interrelated among them that related to quality control and loss of costs for the maintenance which should be minimized, they include: (1) costs of quality inspection, (2) costs of false alarm, (3) costs of manufacturing nonconforming products, (4) costs of location and repairing an assignable cause of the process [11]. In more advanced and according to study, there are some other costs linked to maintenance procedures as loss of costs in equipment's maintenance as an experimental study affirmed and named as a unit which is cost per unit or product controlled (Cc1), cost per nonconforming unit (Cnc), cost per false alarm by unit (Cfa), and cost to locate and repair an assignable cause of the process break down (Crac) [25]. In relation with operating and applied maintenance of equipment in the firms, other costs were mentioned and they were presented as a set of cost criteria which are: (1) sampling cost, (2) cost of process out of control state, (3) cost of process in-control state, (4) cost of false alarms, and (5) cost of investigating assignable cause and maintenance cost, and here the objective is to develop performance of equipment and to reduce additional inspection costs [3]. But there are differences between studies whose works on that topic, they gave between three to four loss of costs related to maintenance, the loss of costs are limited in many other studies collected all other costs, they presented number of mathematical equations should be suitable to get more precise results, for determining loss of costs as precise results, the studies presented a four-loss of costs and showed six mathematical equations $[3,25,26]$ such as follows:

Now in order to find the loss of costs per equipment in an average cycle procedure $(Q)$ which referred as an item by some studies, we should determine four types of loss such as:

1. Q1: the loss of cost of a false signal detection, sampling, inspecting, evaluating, plotting and actually finding, and repairing the assignable cause, they worked as basic costs.

2. Q2: the loss of cost for corrective maintenance.

3. Q3: the in-control average loss of costs.

4. Q4: the expected loss of costs due to poor quality.

At first, in order to find $Q 1$, we need to find type one error probability $(\rho)$, the error probability can be determined and expressed by the equation:

$\rho=1-(P w+P r)$

But both probabilities $(P w+P r)$ at above equation, their values can be determined according to the following two equations:

$$
\begin{aligned}
& P_{w}=\Omega(w)-\Omega(-w) \ldots \ldots \ldots \ldots \ldots \ldots(1 . a) \\
& P_{r}=2 *[(\Omega(k)-\Omega(w)] \ldots \ldots \ldots \ldots \ldots \ldots(1 . b)
\end{aligned}
$$


Then, to find $Q 1$, the equation is expressed as follows:

$Q 1=\rho *\left(\frac{T 0}{h 0}\right) * C p i+(C f u+C v u * s) *\left(\frac{T 0}{h 0}+\frac{T 1+T \operatorname{tap} * S}{h 1}\right)+C r \ldots \ldots \ldots \ldots \ldots \ldots$

Second, in order to find $Q 2$, it needed the following equation:

$Q 2=\operatorname{Cacm} *\left(\operatorname{Pr} *\left(\frac{T 0}{h 0}\right)+\overline{P_{r}} * A R L 1\right)$

Third, in order to find $Q 3$, we need to find other values related to in-control average loss of costs, for this purpose, it will be supposed that the specification limit of quality characteristic is equal to $(\mathrm{m} \pm \Delta)$, where $\mathrm{m}$ is the target value and this will cost $\mathrm{C}_{\mathrm{po}}$ for repairing the equipment, and then bring the shifted process back to in-control state, in that case we can obtain the value of $\left(\mathrm{C}_{\mathrm{po}} / \Delta^{2}\right)$ for the coefficient of loss function.

We suppose that the process is still in-control state, for this, let $d v$ be the difference between the average and target, and $\beta$ be the standard deviation of the process respectively, and where $u$ is a production quantity per unit time. Then the equation of Q3 is as follows:

$Q 3=\frac{C_{p o}}{\Delta^{2}}\left(B^{2}+(d v)^{2}\right)(T 0-h 0+\psi) * u$

Fourth, in order to find expected loss of costs due to poor quality $Q 4$, it represents the expected loss of costs due to poor quality, and it should be determined if an assignable cause occurs, we need for the following equation:

$Q 4=\frac{C_{p o}}{\Delta^{2}}\left(\beta^{2}+(M P * ß+d v)^{2} *(T 1+T t a p * s+T r+h 0-\psi)\right) * u$

Now in order to find the loss of costs per equipment in an average cycle procedure $Q$ which referred as an item by some studies, it assumed a sum of loss of costs and can be expressed in equation 6 :

$Q=Q 1+Q 2+Q 3+Q 4$

It is necessary to know that the goal of economic design of x-control chart is to find the parameters $s, h$, and $k$, they should to be applied in order to minimize loss of costs as showed in the equation 6 , because this equation is regarded as complicated function to variables and to find their values, a study achieved and made coded program by using Matlab 7.6 software, the study should use the program in order to calculate algorithm for solving the optimal design parameters to reach minimum cost [27].

\section{Results and discussion:-}

\section{Results:-}

The following results are noted in this research:

- Economic design of control charts on the topic of loss of costs can be used efficiently.

- Taguchi method can be defined as a quality control methodology, it will: (1) combine control chart, process control with maintenance and process design, (2) assist quality level of maintenance procedures, (3) use statistical method developed to improve quality of manufactured equipment.

- Taguchi method can: (1) overcome bad design of maintenance, (2) be used for many fields of engineering, (3) affirm that the characteristic measurement is the same as the target value, the loss is zero.

- 4 options of quantity, quality, time, and cost are connected to topic of loss of costs of maintenance procedures.

- As a result of machinery and technology of production development, 4 new states were occurred, they are: (1) manufacturing process was shifted with higher ratio from workers to equipment, (2) stronger relationship between product quality and equipment maintenance, (3) larger interrelation between control chart and maintenance, (4) actual integration between control chart and maintenance become more beneficial to firms.

- There were some studies which developed an integrated model of control chart and maintenance management in order to reduce loss of costs. 
- There are 3 variables in economic design of control chart, 3- 5 loss of costs as came by many worldwide studies, and it needed 6 equations and 37 parameters and variables which can be inserted into the economic design of control chart to find loss of costs in the maintenance of equipment in the firm.

\section{Discussion:-}

- This research presented two types of previous and recent studies as literature reviews because to show the improvement and changes of economic design of control chart in two decades, and to know comparison between old and new economic design of maintenance procedure in the firms.

- This research chooses Taguchi method of quality control because:

1. It can recognize the role of research and development in reducing occurrence of defects, failures, and loss of costs which have relation with maintenance procedure.

2. It is observed that this method lies in several quality improvement techniques and mathematical formulas because the method emphasis on minimizing variations.

3. It cannot be affected by outside conditions and daily variations of equipment.

4. It can overcome bad design of maintenance, because the method assists to increase inspection.

5. It uses the statistical technique during maintenance phases, and it can show the complete loss of costs and shifts process to mean and variable

- The role of quality control is assumed as important because:

1. It makes control of main options of quantity, quality, time, and cost of manufactured equipment.

2. It indicates the results because the loss of costs may not occur if the value results equal the same target in maintenance procedure.

3. This concept is widely used in most models of economic design of control charts.

- The loss of costs is different according to various places and firms, but they cover all costs that loss in maintenance of equipment and for one cycle of the procedure.

\section{Conclusions and recommendations:-}

\section{Conclusions:-}

After great development of production machines and technology of equipment, the process of manufacturing in the firms was shifted from workers to equipment, therefore the role of maintenance of equipment increased more than before in order to give continual production and reduce stoppage of equipment during operations, this new state needed for vast control main options of quantity, quality, time, and cost of maintenance of equipment in the firms, it required also more interrelation between control chart and maintenance procedure. The control chart is used to promote quality level of equipment's maintenance, the control chart is a main tool of statistical process control, and the economic design of $\mathrm{x}$-bar control chart and it can ensure lower loss of costs in maintenance procedure, for the out-control state, several mathematical equations will be used in order to operate and evaluate results of maintenance to minimize loss of costs in the procedure, and to show them by a methodology based on Taguchi method of quality control using and by the way of combing four factors of (1) maintenance, (2) loss of costs, (3) x-bar control chart, and (4) quality level.

The first model of economic design of $\mathrm{x}$-control chart was applied and later extended from single to multiple assignable causes in which the failure mechanism was assumed to be an exponential distribution to get three economic design parameters of subgroup or sample size $(s)$, sampling interval $(h)$ and control limit width $(+k)$ or $(-$ $k$ ), and several studied have achieved to improve design of control chart and to find loss of costs after Duncan's first study, they prepared economic design of control charts, also several studies on loss of costs of maintenance between years 1981-1991were prepared, they achieved theoretical development in area of loss of costs, some of them used Taguchi method to find target of loss of costs with more precision input parameters, at later time, a software package in R chart with a new name for economic design of control chart in 2013 was done for industrial application.

But in order to find values of loss of costs in the maintenance of equipment in the firms, there are 25 parameters and variables would be inserted into the economic design of control chart, and related mathematical equations of six formulas will be applied to show how to find those four values of loss of costs, this depends on Taguchi method which was developed by Japanese engineer-statistician Dr. Genichi to define a quality control methodology, and this method at first combines control chart, process control, process design with maintenance procedure, and it can assist quality level of maintenance procedures, and it is used for many fields of engineering and lies in several quality improvement techniques and mathematical formulas. 
The aims of the research are to review previous and recent studies about loss of costs, and to show loss of costs of equipment's maintenance, the research tries to indicate sorts of four loss of costs of maintenance procedure by using Taguchi method, to present mathematical equations of loss of costs in the same procedure, and to show how the process shifts from the original state. The values of loss of costs should be determined to assist the maintenance procedure in the firms to be on-control state and high quality characteristics of equipment activities, hence, in the designated control chart, the aim is to fix a value for the shift $\delta$ of in-control process means $\mu 0$ to out-of-control condition $\mu 1$, and the selecting correct value for shift size can be assumed as a difficult decision by the quality practitioner in the procedure of maintenance, but the overall process under control state and quality characteristic is located between zones of $(\mu \pm \mathrm{w} \beta / \sqrt{\mathrm{s}})$, then, the main goal of economic design of control charts is to reduce cost of maintenance procedure in the firms which include several costs such as: (1) costs of quality inspection, (2) costs of false alarm, (3) costs of manufacturing nonconforming products, (4) costs of location and repairing an assignable cause of the process, and several other costs can be included which worked as basic costs, and the studies showed six mathematical equations to present a four-loss of costs for corrective maintenance with in-control average loss of costs and the expected loss of costs due to poor quality.

\section{Recommendations:-}

We recommend to use control chart to promote quality level of equipment of production processes in the firms, and use economic design of $\mathrm{x}$-bar control chart which ensure lower loss of costs in the maintenance of equipment, also in order to show the loss of costs in the firms by using Taguchi method of quality control, it is also recommended to apply related mathematical equations to investigate the working and result of maintenance of equipment and in order to minimize loss of costs in the firms, and as well as it is recommended to control main options of quantity, quality, time, and cost of manufacturing equipment in the firms and make new developments by interrelation between control chart and maintenance.

\section{References:-}

1. Santiago Omar Caballero Morales, Economic Statistical Design of Integrated X-bar-S Control Chart with Preventive Maintenance and General Failure Distribution, Technological University of the Mixteca, Huajuapan de Leon, Oaxaca, Mexico, 2013, Plos one, open access.

2. Duncan AJ, The economic design of charts when there is a multiplicity of assignable causes. Journal of the American Statistical Association, 1971, No. 66, pp 107-121.

3. Wei-Shing Chen, Fong-Jung Yu, Ruey-Shiang Guh, and Yu-Hua Lin, 2011, Economic design of x-bar control charts under preventive maintenance and Taguchi loss functions, ISSN 1735-8523 (Print), ISSN 1927-0089 (Online), Journal of Applied Operational Research, 2011, Vol. 3 (2), pp 103-109.

4. Sündüs DA, Real Application on Economic Design of Control Charts with R-edcc Package, The International Journal of Engineering and Science (IJES), Vol. 4, Issue 10, 2015, pp 54-65, ISSN (e): 2319 - 1813 ISSN (p): 2319 - 1805.

5. D.C. Montgomery, Economic design of an X control chart, Journal of Quality Technology, 1982, Vol. 14 (1), pp 40-43.

6. Von Collani E, A simple procedure to determine the economic design of an control chart. Journal of Quality Technology, 1986, Vol. 18, pp 145-151.

7. Lorenzen TJ and Vance LC, The economic design of control charts: a unified approach. Technimetrics, 1986, Vol. 28, pp 3-10.

8. Ho C and Case KE, Economic design of control charts: A literature review for 1981-1991. Journal of Quality Technology, 1994, Vol. 26, pp 39-53.

9. Ben-Daya M and Duffuaa SO, Integration of Taguchi's loss function approach in the economic design of chart. International Journal of Quality and Reliability Management, 2002, Vol. 20, pp 607-619.

10. Serel DA, Economic design of EWMA control charts based on loss function. Mathematical and Computer Modeling, 2009, Vol. 49, pp 745-759.

11. Antonio F. B. Costa, Fernando A. E. Claro, Economic Design of X (dash)Control Charts for Monitoring a First Order Autoregressive Process, Brazilian Journal of Operations \& Production Management, 2009, Vol. 6, No. 2, pp. 07-26

12. ] Ling Yang, Yuh-Rau Wang, and Suzanne Pai, Statistical and economic analyses of an EWMA-based synthesized control scheme for monitoring processes with outliers, International Journal of Systems Science, February 2012, Vol. 43, No. 2, pp. 285-295. 
13. W. Zu, and C. Park, An R package for the economic design of the control chart, Journal of Statistical Software, 2013, Vol. 52(9), pp 1-24.

14. www.businessdictionary.com/definition/Taguchi-method.html/definition/quality-control-QC.html /definition/quality-improvement.html /definition/quality criteria.html

15. Srinivas Athreya, Y.D.Venkatesh, Application of Taguchi Method for Optimization of Process Parameters in Improving The Surface Roughness of Lathe Facing Operation, International Refereed Journal of Engineering and Science, Nov. 2012, Vol. 1, Issue 3, (IRJES) ISSN (Online) 2319-183X, (Print) 2319-1821, pp 13-19.

16. Hazura Mohamed, Muhammad Hisyam Lee, Bahrom Sanugi, Mazalan Sarahintu, Taguchi Approach for Performance Evaluation of Routing Protocols in Mobile Ad Hoc Networks, Journal of Statistical Modeling and Analytics, 2010, Vol. 1 No. 2, pp. 10-18.

17. www.businessdictionary.com/definition/Taguchi-method.html/definition/quality-control-QC.html /definition/quality-improvement.html /definition/quality criteria.html

18. Aravindan and S.R. Devadasan, B.V. Dharmendra, V. Selladurai, Continuous quality improvement through Taguchi's online quality control methods, International Journal of Operations \& Production Management, 1995, Vol. 15, No. 7, pp. 60-77. MCB, University Press, 0144-3577, page 62.

19. Jasmina Mikovic, Sandra Velickovic, SrbislavAleksandrovic, Dobrivoje Catic, Application of Taguchi methods in testing tensile strength of polyethylene, 8th International Quality Conference May 23rd 2014, Center for Quality, Faculty of Engineering, University of Kragujevac, Page 575- 576.

20. Mc Kone KE, Schroeder RG and Cua KO, The impact of total productive maintenance practices on manufacturing performance. Journal of Operations Management, 2001, Vol. 19, pp. 39-58.

21. Ben-Daya M, Integrated production maintenance and quality model for imperfect process, 1999, IIE Transactions

22. Chang CP, Chin H, Hsiao YD and Yu FJ, Effect of Preventive Maintenance on the Economic Design of Control Chart, The 13th IFAC Symposium on Information Control Problems in Manufacturing, 2009, Moscow, Russian, pp. 1688-1691.

23. M. A. A. Cox, 2013, An Approximate Approach to the Economic Design of x Charts By Considering the Cost of Quality, Journal of Modern Applied Statistical Methods, May 2013, Vol. 12, No. 1, 170-180, JMASM, Inc., 1538 - 9472, page 170 .

24. Giovanni Celano, On the constrained economic design of control charts: a literature review, Produção, Jun. 2011, Vol. 21, No. 2,. University of Catania, Italy, pp. 223-234.

25. Rok Zupančič, Alojzij Sluga, 2008, Economic Design of Control Charts, Strojniški vestnik - Journal of Mechanical Engineering, 2008, Vol. 54, No. 12, pp. 855-865.

26. S.S.N. Murthy, Y. Rambabu, Design and Application of Economical process Control charts, Defense science journal, January 1997, Vol. 47, No. 1, pp 45-53.

27. Rahim MA and Banerjee PK, A generalized model for the economic design of control chart for production systems with increasing failure rate and early replacement, Navel Research Logistics, 1993, Vol. 40, pp. 787809. 